Atıf için / For Citation: M. ŞAHAN, "Osmaniye'de iki yıl boyunca güneşin ultraviyole (385-295 nm) 1şı1ımının ölçülmesi”, Süleyman Demirel Üniversitesi Fen Edebiyat Fakültesi Fen Dergisi, 14(2), 227-238, 2019.

\title{
Osmaniye’de İ́ki Yıl Boyunca Güneşin Ultraviyole (385-295 nm) Işınımının Ölçülmesi
}

\author{
Muhittin ŞAHAN ${ }^{* 1}$ \\ ${ }^{1}$ Osmaniye Korkut Ata Üniversitesi, Fen Edebiyat Fakültesi, Fizik Bölümü, 80000, Osmaniye, Türkiye \\ *yazışllan yazar e-posta: muhittinsahan@osmaniye.edu.tr
}

(Alınış / Received: 28.05.2019, Kabul / Accepted: 16.08.2019, Yayımlanma / Published: 30.11.2019)

Özet: Bu çalışmada Güneşten gelen ultraviyole (UV) 1şınımının iki yıllık (Ocak 2015-Aralık 2016, toplam 717 gün) ölçüm sonuçlarını vermektedir. Yatay yüzeye gelen UV 1şınımı (295$385 \mathrm{~nm}$ ) ölçmek için Osmaniye Korkut Ata Üniversitesi Karacaoğlan Yerleşkesinde (Enlem: 37.04D, Boylam 36.22K) bulunan Eppley UV Radyometresi kullanılmıştır. Tüm UV 1şınım verileri $\mathrm{W} / \mathrm{m}^{2}$ cinsinden saatlik, günlük ve aylık olarak işlendi ve analiz edildi. Günlük veriler kullanılarak en yüksek aylık ortalama UV radyasyonu $19.56 \mathrm{~W} / \mathrm{m}^{2}$ ile Haziran ve $19.56 \mathrm{~W} / \mathrm{m}^{2}$ ile Temmuz'da elde edilmiştir. Aylık olarak ortalama en yüksek saatlik UV değerleri yine Haziran'da $33.00 \mathrm{~W} / \mathrm{m}^{2}$ olarak ve Temmuz'da $34.51 \mathrm{~W} / \mathrm{m}^{2}$ olarak ölçüldü (öğle saatlerinde). İki yıl boyunca UV 1şınımın toplam ve ortalama miktarı sırasıyla $4911.82 \mathrm{~W} / \mathrm{m}^{2}$ ve $11.83 \mathrm{~W} / \mathrm{m}^{2}$ olarak hesaplanmıştır. Güneşten gelen toplam ve UV ışınım verileri arasında lineer regrasyon ilişkisi kurulmuş ve $\mathrm{R}^{2}=0.93$ olarak bulunmuştur.

Anahtar kelimeler: UV Işınımı, UV radyometresi, Dünya yüzeyine gelen radyasyon, UV ışınımın uzun süreli değişimi

\section{The Measurement of Solar Ultraviolet $(385-295 \mathrm{~nm})$ Radiation During Two Years Period in Osmaniye}

Abstract: The present study gives the measurement results of the solar ultraviolet (UV) irradiance for 2-year period (January 2015 to December 2016, total 717 days). An Eppley UV radiometer was used to measure solar UV irradiance $(295-385 \mathrm{~nm})$ on a horizontal surface on Karacaoglan Campus, Osmaniye Korkut Ata University (latitude: $37^{\circ} .04 \mathrm{E}$, longitude: $36^{\circ} .22 \mathrm{~N}$ ). All of the solar ultraviolet irradiance data were performed and analyzed as hourly, daily and monthly in unit of $\mathrm{W} / \mathrm{m}^{2}$. The highest monthly average UV radiation from daily data took place in June with a value of $19.56 \mathrm{~W} / \mathrm{m}^{2}$ and in July with a value of $19.50 \mathrm{~W} / \mathrm{m}^{2}$. Maximum monthly average hourly UV radiation were also measured in June with a value of $33.00 \mathrm{~W} / \mathrm{m}^{2}$ and in July with a value of $34.51 \mathrm{~W} / \mathrm{m}^{2}$ (at solar noon). The total accumulated and mean UV irradiation along two average years reached $4911.82 \mathrm{~W} / \mathrm{m}^{2}$ and $11.83 \mathrm{~W} / \mathrm{m}^{2}$, respectively. Linear relationships were established between $\mathrm{UV}$ and global solar radiation data with the $\mathrm{R}^{2}=0.93$.

Key words: UV Radiation, UV radiometer, Earth surface radiation, long term UV changes

\section{Giriş}

UV 1şınımı, Güneş'in dünya yüzeyine ulaşan enerjisinin belirli bir bölümünü ifade eder. Güneşten çıkan ve yeryüzüne gelen ultraviyole (UV) 1şınımı güneş enerjisinin belirli bir bölümünü içermekte ve çevresel etkilerinin bilinmesi birkaç sebeplerden dolayı önemlidir. Yer yüzündeki tüm canlıların oluşumu ve gelişimi UV 1şınımı dahil birçok 
çevresel değişkenden etkilenmektedir. İnsan, bitki ve hayvan organizmaları üzerindeki etkisi kanser araştırmaları, tarım ve ormancılık gibi çok çeşitli alanlarda önemlidir. Atmosferdeki ozon tabakasının incelmesine dünyadan atmosfere yayılan kloroflorokarbon gazlarının miktarının artmasının neden olduğu bilinmektedir. Ayrıca, insanlar giyim tarzları, meslekleri, değişen yaşam şartları, yaşları ve yaşadıkları bölgenin enlem ve boylamları gibi çeşitli faktörlerden dolayı UV 1şınımına maruz kalmaktadırlar. Son yıllarda dünya yüzeyine gelen UV ışınımda artış gözlenmesinden dolayı UV 1şınım ölçümleri daha da önem kazanmıştır. UV 1şınımı, güneşten gelen toplam ışınımın küçük bir kısmını temsil etmesine rağmen, özellikle birçok organizma için oldukça zararlı olan bazı biyolojik ve kimyasal etkilere neden olmaktadır. Bu nedenle, insanların UV radyasyonuna uzun süre maruz kaldıklarında cilt kanserine, göz kataraktlarına ve bağışıklık sisteminin zayıflamasına neden olmaktadır. Bu nedenle UV 1şınımının bölgesel olarak ölçülmesi ve kısa ve uzun sürede etkilerinin takip edilmesi önemlidir [1-3].

Güneşten gelen UV ışınımı elektromanyetik tayfın $200 \mathrm{~nm}$ ile $400 \mathrm{~nm}$ arasındaki bir bölümünde yayılan enerji olarak karakterize edilmektedir. UV spektrumu, fiziksel ve biyolojik özelliklerinde farklılık gösteren UV-C (200-280 nm), UVB (280-315 nm) ve UVA (315-400 nm) olmak üzere üç bölgeye ayrılmaktadır. Güneşten gelen UV 1şınımının bir kısmı dünyanın üst atmosferdeki oksijen $\left(\mathrm{O}_{2}\right)$ ve ozon $\left(\mathrm{O}_{3}\right)$ (stratosferik ozon) tarafindan soğrulması sonucu yeryüzüne gelen toplam enerjisinin sadece yaklaşık \% 5'lik çok küçük bir kesrini oluşturmaktadır [4,5]. UV-C'in tamamı, UV-B'nin ise bir kısmı dünyanın üst atmosferindeki ozon tabakasında soğrulduğundan yer yüzeyine ulaşamaz. Bulutsuz açık bir günün öğle saatlerinde yeryüzüne gelen bu ışınımın yaklaşık \% $\%$ 'i UV-B ve \% 95'i ise UV-A radyasyonundan oluşmaktadır [5-8].

UV-B ışınımı amino-asitler ve nükleik-asitler tarafından emilmesinden dolayı canlılar üzerinde olumsuz etkilere sahiptir. Bu nedenle ozon tabakasının incelmesi dünya yüzeyine daha fazla UV-B 1şınımının gelmesi anlamına gelmektedir. Daha düşük şiddete sahip olan UV-A 1şınımı ozon tabakasında çok az soğrulur ve stratosfer tabakasını geçerek yere kadar ulaşır. İnsan sağlığı için gerekli olan D vitaminin sentezlenmesi için gereklidir. UV-A 1şınımı derinin daha alt kısımlarına kadar etki yaparak, öncelikle cildin koyulaşmasına neden olmakta ve deri kanserinin gelişimini de artırmaktadır $[1,2,6-8]$.

UV 1şınımının canlılar üzerindeki etkilerinden dolayı Dünya Meteoroloji Örgütü (WMO), Dünya Sağlık Örgütü (WHO), üniversiteler gibi pek çok kuruluş tarafından önemli çalışmalar yapılmıştır. Yapılan çalışmalara göre, yeryüzünde gelen UV ışınım şiddeti güneşin yüksekliğine, ölçüm yapılan yerin enlemine ve yüksekliğine, atmosferik ve yersel koşullara bağlı olarak uzaysal ve zamansal pek çok değişimlere bağlı olduğu görülmüştür. Örneğin, yeryüzüne gelen yıllık UV ışınım miktarı dünyanın eğikliğinden dolayı ekvatordan kutuplara doğru gidildikçe azalırken, deniz seviyesinden yüksek rakımlara gittikçe artış göstermektedir [1]. Ilıman bölgelerde, Dünya yüzeyine ulaşan UV 1şınımı mevsimlere bağlı olarak değişiklik göstermektedir. Ayrıca, bulutlar UV radyasyonunun dünyaya ulaşmasını engellediğinden dolayı kış mevsiminde daha az miktarda UV radyasyonu yeryüzüne ulaşmaktadır. UV ışınımı miktarı Güneş ışınlarının gelme açısından dolayı yaz mevsiminde kış mevsiminde olduğundan daha düşüktür. Günlük Toplam UV 1şınımının yaklaşık \%20-30'u yaz aylarında ve bunun da \%75'i saat 9:00 ile 15:00 arası olan gün ortasında alınmaktadır. [1]. 


\section{Materyal ve Metot}

Son yıllarda stratosferik ozon tabakasının hızla azalmasıyla birlikte çeşitli alanlarda yeni araştırma programlarının başlatılması hız kazanmıştır. Dünya Sağlık Örgütü’ne (WHO) göre, her yıl binlerce insan küresel olarak cilt kanseri hastalığına, cilt yaşlanması ve göz hasarı gibi bazı önemli hastalıklara neden olmaktadır. Güneşten gelen UV ışınım verilerine olan talep belirgin şekilde artmış ve buna ek olarak birçok araştırmacı da genellikle çeşitli detektörler kullanarak kendi UV 1şınım ölçümlerini yapmaya başlamışlardır. $\mathrm{Bu}$ amaçla, güneşten gelen UV 1şınımını ölçmek ve yıllık olarak değişimini incelemek amaciyla Osmaniye Korkut Ata Üniversitesi Merkez Karacaoğlan yerleşkesinde $\left(37^{\circ} .042 \mathrm{~K}, 36^{\circ} .22 \mathrm{D}\right)$ Mayıs 2013 tarihinden itibaren UV 1şınımını dakikalık olarak günlük ölçülmektedir. UV ışınımının ölçülmesinde Eppley tipi toplam UV-radyometre (Eppley Total Ultraviolet Radiometer: TUVR ${ }^{1}$ ) ölçüm cihazı kullanılmaktadır. Şekil 1'de verilen TUVR cihazı güneşten gelen 295-385 nm ( UVA+UVB) aralığındaki UV 1şınımını mili volt cinsinden dakikalık olarak ölçmektedir. TUVR cihazı kuvars bir pencere ile korunan, hava geçirmeyecek şekilde kapatılmış bir selenyum bariyer tabakası hücresini kullanmaktadır. Özel olarak tasarlanmış teflon iyi bir kosinüs tepkisi sağlamaktadır. Kapsüllü bir dar bant geçiren (parazit) filtre 385-295 $\mathrm{nm}$ aralık dalga boyu fotosel spektral tepkisini sinırlayan 150 $\mu \mathrm{V} / \mathrm{Wm}^{-2}$ duyarlılı̆̆ına sahiptir ve $0-10 \mathrm{mV}$ analog aralığında çıktı vermektedir.

UV radyometreden alınan sinyaller Şekil 1'de gösterilen 16 bit girişli olan 16 kanallı, 420 mA akım döngüsünü sahip MS6D model veri kaydedicisine (Data Logger) dakikalık olarak mili volt cinsinden bir gün boyunca toplam 1440 adet veri kaydedilmektedir. Daha sonra $\mathrm{mV}$ cinsinden dakikalık olarak elde edilen bu veriler kişisel bir bilgisayara aktarılmakta ve gerekli kalibrasyonu yapılarak $\mathrm{W} / \mathrm{m}^{2}$ birimde saatlik, günlük, aylık ve yıllık olarak analiz edilmekte ve bir veri arşivi oluşturulmaktadır. Şu anda, MS6D Data Logger sadece Güneşten gelen toplam 1şınımı ölçen 8-48 Model Black and White Pyranometeresinden ve UV 1şınım bileşeninin ölçen Eppley tipi UV radyometresinden gelen iki veriyi kaydetmek kullanılmaktadır $[9,10]$.

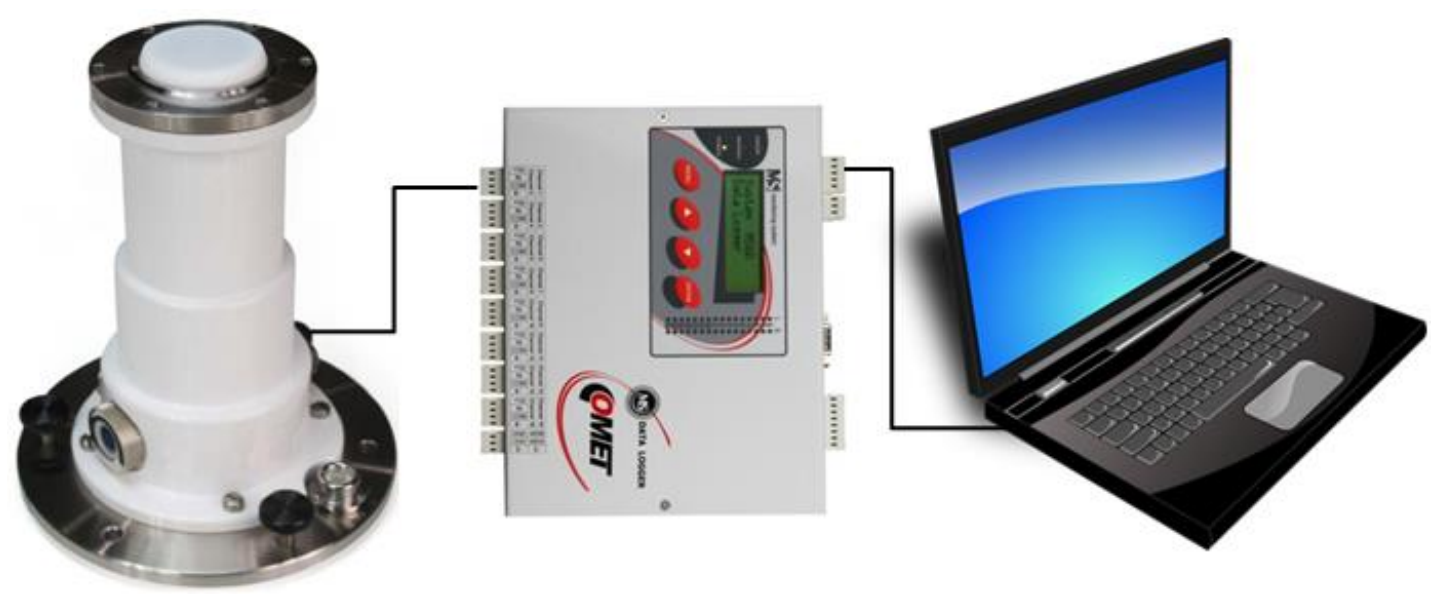

Şekil 1. Eppley tipi UV radyometre (Eppley Total Ultraviolet Radiometer: TUVR) ve Veri toplama sistemi

${ }^{1}$ http://www.eppleylab.com/instrument-list/total-ultraviolet-radiometer/ 


\section{Bulgular}

Bu çalışmada 1 Ocak 2015 ile 31 Aralık 2016 tarihleri arasında toplam 717 günlük UV 1şınım verisi kullanılmıştır. 22 Eylül 2016 tarihinden 04 Ekim 2016 tarihine kadar olan diğer 13 günlük sürede veri kaydı yapılamamıştır. UV radyasyonu gün boyunca dakikalık olarak mili volt $(\mathrm{mV})$ cinsinden ölçülmüştür. $\mathrm{mV}$ cinsinden dakikalık olarak ölçülen veriler kalibrasyon yapılarak $\mathrm{W} / \mathrm{m}^{2}$ birimine dönüştürülmüştür [10].

Veri kaydedicisi (Data Logger) 24 saat boyunca sürekli olarak $\mathrm{mV}$ cinsinden dakikalık olarak veri kaydedilmektedir. Güneş ufuk düzleminin altına indikten sonra gece boyunca UV radyasyonu gelmediğinden TUVR ölçüm cihazı gürültü olarak adlandırdığımız ve değerleri negatif olan veri kaydetmektedir. Veri kaydedicisinde depolanan bu toplam veriler belirli zamanlarda alınarak kişisel bilgisayara aktarılmaktadır. IDL (The Interactive Data Language) programlama dilinde yazılan kodlar kullanılarak tüm yıl boyunca güneşin doğuş batış süreleri belirlenmiş ve güneşin ufuk düzleminin altında olduğu zamanki negatif veriler temizlenerek sadece güneş ufuk düzleminin üzerindeyken gelen günlük $\mathrm{mV}$ cinsinden UV ışınım verileri elde edilmiş ve analizlere hazır hale getirilmiştir. Dakikalık olarak $\mathrm{mV}$ cinsinden alınan tüm günlük toplam UV ışınım bileşenleri veri analizleri yapılarak saatlik, günlük, aylık ve yıllık olarak ayrı ayrı W/m² cinsinden hesaplanmıştır. 2015-2016 yılları arasında ölçülen ve analiz edilen iki yıllık toplam UV verilerinin sonuçları aşağıda detaylı olarak verilmiştir.

Dakikalık olarak $\mathrm{W} / \mathrm{m}^{2}$ cinsinden elde edilen günlük UV değişimine örnek olarak havanın açık ve kapalı olduğu iki farklı günlük veri seçilmiş ve UV'nin günlük değişimine bakılmıştır. Havanın açık (yani bulutsuz) olduğu bir gün olarak seçilen 25 Haziran 2016 tarihinde sabah saat 05.22'den başlayarak akşam saat 19:48'ye kadar toplam 867 adet dakikalık veri alınmış ve elde edilen günlük değişim Şekil 2a'da gösterilmiştir. Şekil 2a'da görüldüğü gibi, hava açı olduğunda güneşin konumuna göre UV 1şınımında düzgün sinüzoidal bir değişim görülmektedir. Gün boyunca alınan veriler sabah ve akşam saatlerinde minimum, öğle saatlerinde güneş tam tepedeyken maksimum olmaktadır. UV radyasyonu en düşük olduğu güneş henüz sabah saat 05:22'de ufuktan yükselirken $0.3 \mathrm{~W} / \mathrm{m}^{2}$ ve zenit olarak adlandırdığımız tepe noktasına ulaştı̆̆ zaman olan $12: 57$ 'de $36.77 \mathrm{~W} / \mathrm{m}^{2}$ ve tekrar azalarak gün batımında $0.23 \mathrm{~W} / \mathrm{m}^{2}$ olarak ölçülmüştür. 25 Haziran 2016 tarihinde gün boyunca radyometreden ölçülen UV 1şınımın toplam miktarı $17277.43 \mathrm{~W} / \mathrm{m}^{2}$ ve günlük ortalama miktarı ise $19.90 \mathrm{~W} / \mathrm{m}^{2}$ ' dir. Benzer şekilde havanın kapalı olduğu 30 Aralık 2016 tarihinde sabah saat 06:49'dan başlayarak akşam saat 16:26'ya kadar toplam 578 dakikalık veri alınmış ve elde edilen günlük değişim sonuçları Şekil 2b'de verilmiştir. Şekil 2b'de görüldüğü gibi hava gün boyunca parçalı bulutlu olduğundan gün boyunca UV 1şınımında sürekli değişiklik görülmektedir. Havanın en açık olduğu saat 11:03'de ölçülen UV radyasyonu maksimum $8.68 \mathrm{~W} / \mathrm{m}^{2}$ olarak ölçülürken, havanın kaplı olduğu öğle saatlerinde (saat 11:44'de $0.73 \mathrm{~W} / \mathrm{m}^{2}$ ) olarak ölçülmüştür. Hava kapalıyken gün boyunca toplam UV değeri $1259.13 \mathrm{~W} / \mathrm{m}^{2}$ (ortalama $2.18 \mathrm{~W} / \mathrm{m}^{2}$ ) olarak belirlenmiştir. Yukarıda belirtildiği gibi UV 1şınımı havadaki su molekülleri tarafından tutulduğundan bulutlu günlerde havanın açık olduğu bir güne göre daha az 1şınım birim yüzeye gelmektedir. 

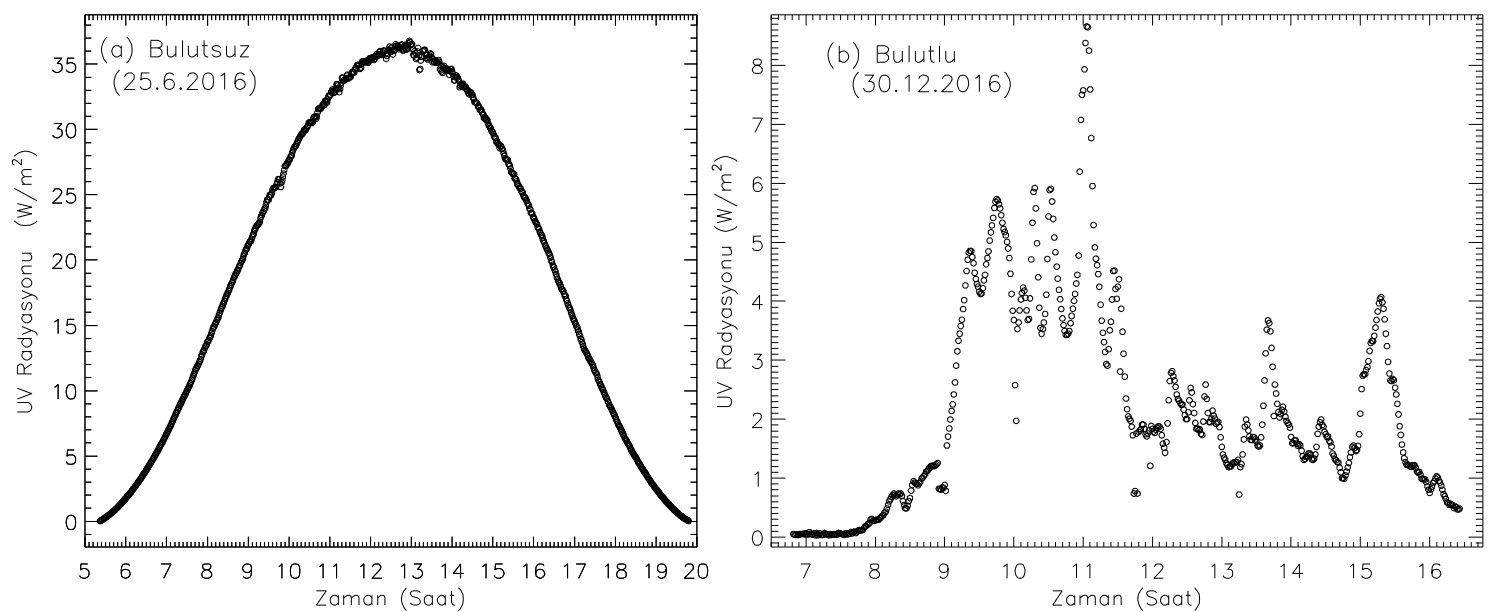

Şekil 2. Havanın bulutsuz (a) ve bulutlu (b) olduğu günlerde yatay yüzeye gelen UV radyasyonunun dakikalık değişimi.

İki yıllık günlük ortalama UV radyasyonun 1 Ocak tarihinden başlayarak 31 Aralık tarihine kadar değişiminin güneşin zenit ve deklinasyon açılarına göre değişimi Şekil 3'de verilmiştir. UV 1şınımları 2015 ve 2016 yıllarına ait günlük UV 1şınımlarının ortalaması alınarak elde edilmiştir. Şekil 3'de yatay eksen yılın günlerini, birinci düşey eksen UV ışınım şiddetini, ikinci ve üçüncü düşey eksenler ise sırasıyla güneşin zenit ve deklinasyon açılarını göstermektedir. 1 Ocak tarihinde $6.73 \mathrm{~W} / \mathrm{m}^{2}$ 'den başlayarak 25 Haziran tarihinde en yüksek şiddet olan $22.59 \mathrm{~W} / \mathrm{m}^{2}$ 'ye ve daha sonra tekrar azalarak 31 Aralıkta $6.31 \mathrm{~W} / \mathrm{m}^{2}$ değerini düşmüştür. Aynı şekilde güneş ufuk düzlemin iken (en yüksek zenit açısı) en düşük UV ışınım şiddetine sahipken ufuk düzleminden itibaren yükselerek zenite yaklaştığında en yüksek UV ışınım şiddetine sahiptir.

Bilindiği gibi Kuzey Yarıüre de 21 Mart tarihi (80. gün) İlkbahar ekinoksu ve 21 Eylül tarihi (266. gün) ise Sonbahar ekinoksu olup güneş 1şınları öğle saatlerinde Ekvator'a $90^{\circ}$ lik bir açı ile düşer. Kuzey Yarımküre de 21 Haziran tarihinde (en uzun gündüz, 172. gün) yaz gündönümü, 21 Aralık tarihinde ise kış gün dönümüdür (en kısa gündüz, 355. gün). Şekil 3'de görüldüğü gibi güneşin deklinasyon ve zenit açıları ekinoks noktalarında (21 Mart ve 21 Eylül) sirasıyla $0.0^{\circ}$ ve $37.0^{\circ}$ 'dir ve deklinasyon ve zenit açılarının kesiştiği noktalardır. Gün dönüm noktalarında deklinasyon ve zenit açıları en yüksek ve en düşük değerlerini göstermektedir. Dünya-Güneş doğrultusunun yerin ekvator düzlemi ile yaptığı deklinasyon açısı 21 Haziran tarihinde $+23.5^{\circ}$ ile maksimum (zenit açıs1 $13.6^{\circ}$ minimumu) gösterirken 21 Aralık tarihinde $-23.5^{\circ}$ ile minimumu ( zenit açıs1 $60.0^{\circ}$ maksimum) göstermektedir. Şekil 3'de görüldüğü gibi, güneşten gelen UV ışınımının şiddeti birincil düşey eksende, güneşin deklinasyon ve zenit açıları ise ikincil düşey eksende gösterilmiştir. Güneşin deklinasyon açısı artarken (zenit açısı azalırken) UV ışınım şiddeti de artmakta ve azalırken de azalmaktadır. Dolayısıyla gün dönüm noktalarında da yaklaşık maksimum ve minimumu göstermektedir. 2015 ve 2016 yıllarına ait günlük ortalama UV 1şınımı şiddeti sırasıyla 21 Mart tarihinde 7.47 $\mathrm{W} / \mathrm{m}^{2}, 21$ Haziran'da $19.29 \mathrm{~W} / \mathrm{m}^{2}, 21$ Eylül'de $12.8 \mathrm{~W} / \mathrm{m}^{2}$ ve 21 Aralık'ta $7.17 \mathrm{~W} / \mathrm{m}^{2}$ olarak elde edilmiştir. 


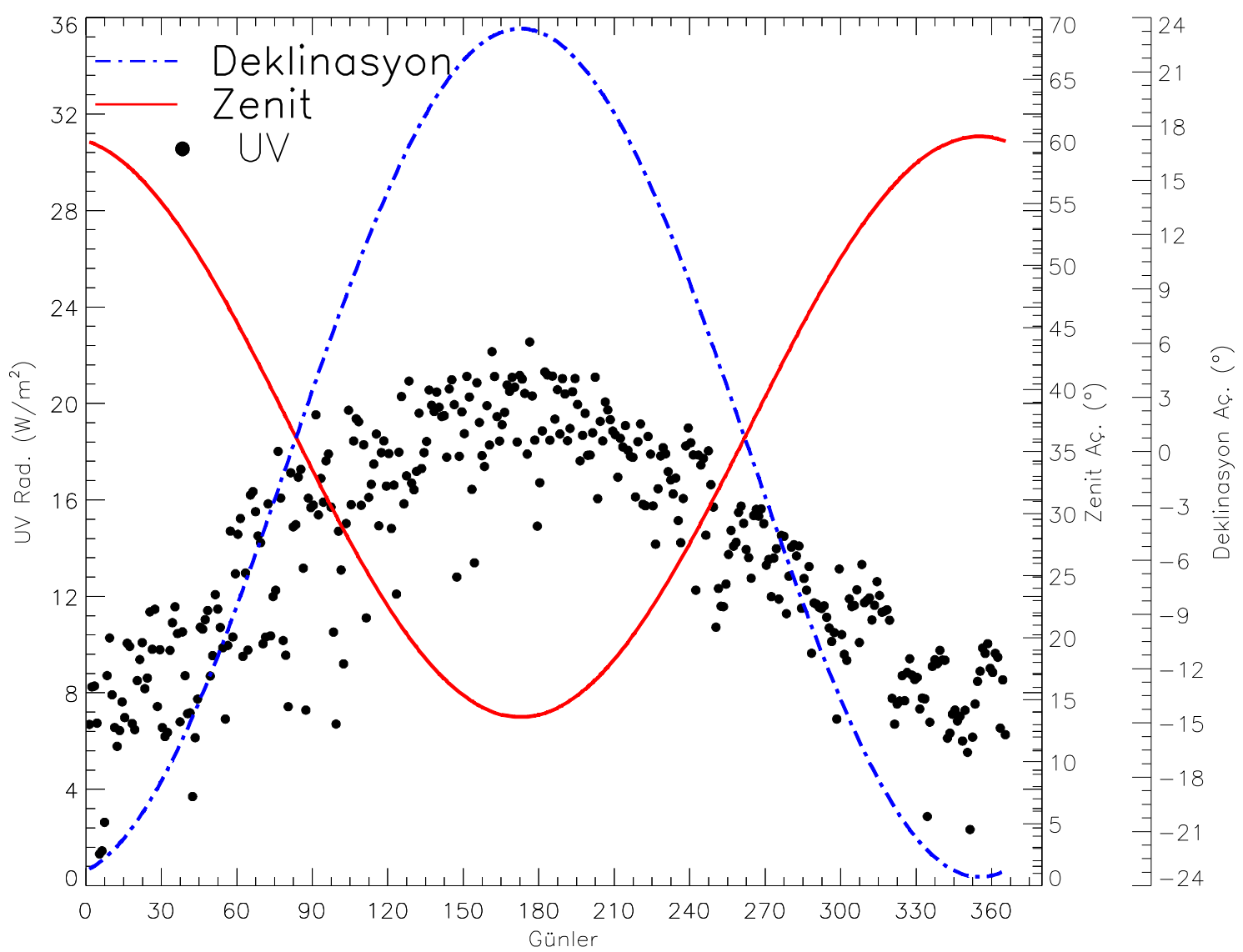

Şekil 3. İki yıllık günlük ortalama UV radyasyonun Güneşin Zenit Açısına ve Deklinasyon açısına göre değişimi.

2015 ve 2016 yıllarına ait iki yıllık günlük ortalama UV 1şınımlarının yıllık olarak değişimleri Şekil 4'de verilmiştir. Şekil 4'de görüldüğü gibi yıllara göre UV 1şınımı değișim eğrisi gün dönüm noktaları civarında en yüksek (Haziran-Temmuz) ve en düşük (Aralık-Ocak) olan sinüzoidal bir eğri şeklindedir. $\mathrm{Bu}$ değişim güneşin deklinasyon açısındaki değişiklikten (Şekil 3) ve atmosferdeki ozon miktarının yıllık değişiminden kaynaklanmaktadır [2]. Havanın bulutluluğuna bağlı olarak UV şiddetindeki uzun ve kısa düşüşler açıkça görülmektedir. UV ışınımı değişim eğrisi en yüksek yaz aylarında (Haziran-Temmuz) en düşük kış aylarında (Aralık-Ocak) olduğu görülmektedir. Şekil 4'de görüldüğü gibi 2015 y1lında ölçülen günlük ortalama UV 1şınımı en düşük ve en yükssek değişimleri sırasıyla $1.25 \mathrm{~W} / \mathrm{m}^{2}$ ve $25.39 \mathrm{~W} / \mathrm{m}^{2}$ (ortalama $13.84 \mathrm{~W} / \mathrm{m}^{2}$ ) iken 2016 yilında sirasiyla $1.47 \mathrm{~W} / \mathrm{m}^{2}$ ve $22.55 \mathrm{~W} / \mathrm{m}^{2}$ (ortalama 13.89 $\mathrm{W} / \mathrm{m}^{2}$ ) olarak ölçülmüştür. 


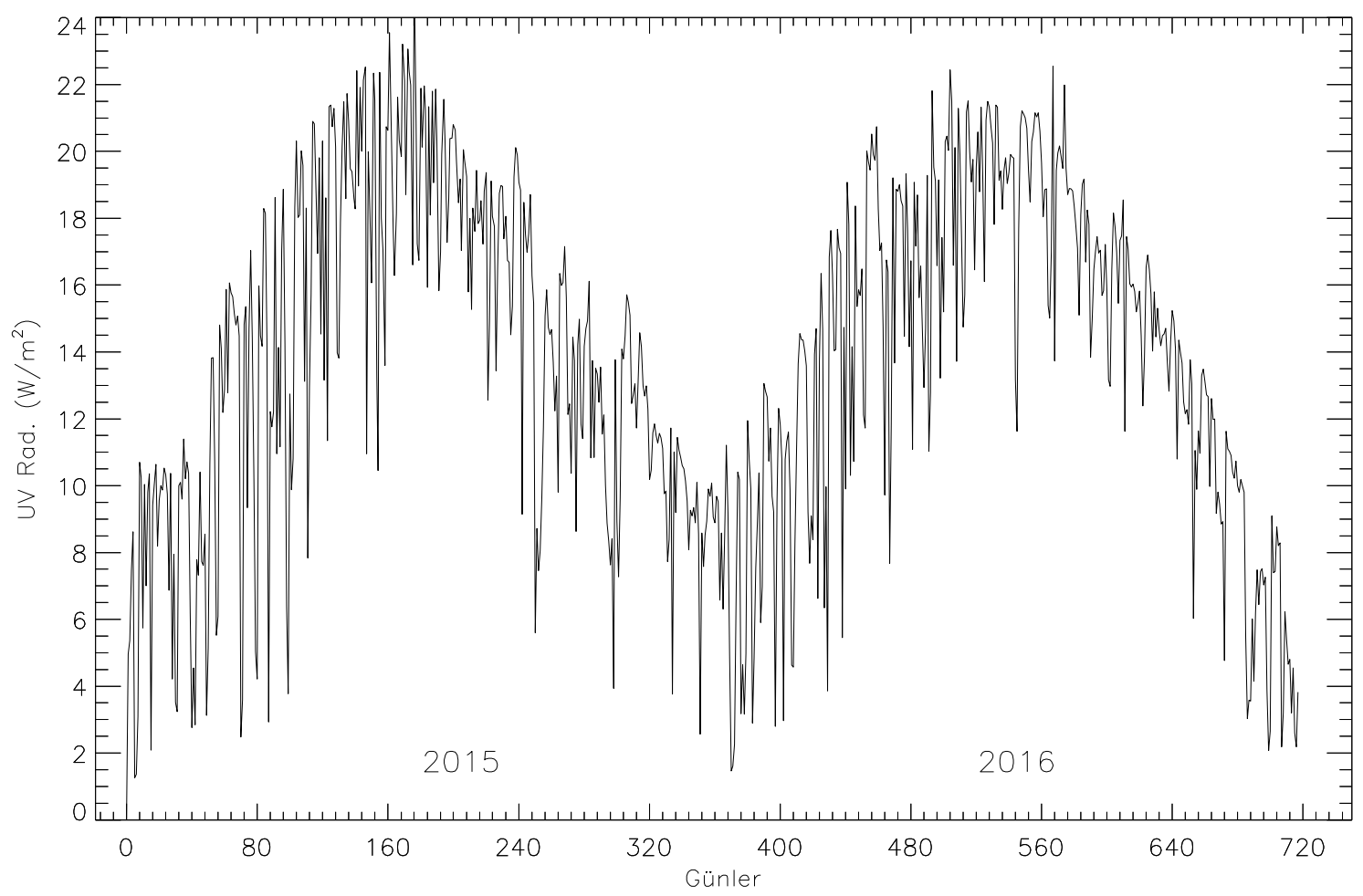

Şekil 4. 2015 ve 2016 yıllarına ait günlük olarak ortalama UV ışınımının yıllık değişimi.

Yıllara göre ölçülen günlük UV 1şınım verileri 2015 yılında 365 gün ve 2016 yılında 352 gün, olmak üzere toplam 717 günlük veriden oluşmaktadır. Her veri için günlük ortalama değerleri hesaplanmış ve yıllık olarak ortalama UV ışınımının değişimi elde edilmiştir. Güneşten gelen ortalama günlük toplam (Global: GL) 1şınım ile UV ışınımının arasındaki ilişkiye inceleme amacıyla lineer regresyon analizi yapılmış ve elde edilen korelasyon grafiği Şekil 5'de verilmiştir. Şekil 5'de global 1şınım yatay eksende ve UV 1şınımı ise düşey eksende verilmiştir. Yapılan lineer regresyon analizi sonucunda, güneşin global 1şınımı ile UV ışınımı arasında doğrusal bir ilişki olduğu görülmüştür. Global ve UV ışınımlarının en düşük değerleri sırasıyla yaklaşık 25.43 $\mathrm{W} / \mathrm{m}^{2}$ ve $1.25 \mathrm{~W} / \mathrm{m}^{2}$ olarak elde edilmiştir (25 Ocak 2015). Global 1şınımın en yüksek değeri yaklaşı $652.99 \mathrm{~W} / \mathrm{m}^{2}$ iken UV 1 şınım da buna bağlı olarak artmış ve 25.43 $\mathrm{W} / \mathrm{m}^{2}$ değerine ulaşmıştır (25 Haziran 2015). Buna göre UV ve global 1şınım arasında " $U V=0.036 G L+0.178$ " gibi bir ilişkinin olduğu görülmüş ve $\mathrm{R}^{2}$ değeri $0.93(\% 93)$ olarak bulunmuştur. Dolayısıyla, güneşten gelen toplam 1 şınım güneşin deklinasyon açısına bağlı olarak artarken UV ışınımı da buna bağlı olarak artmaktadır (Şekil 3). 


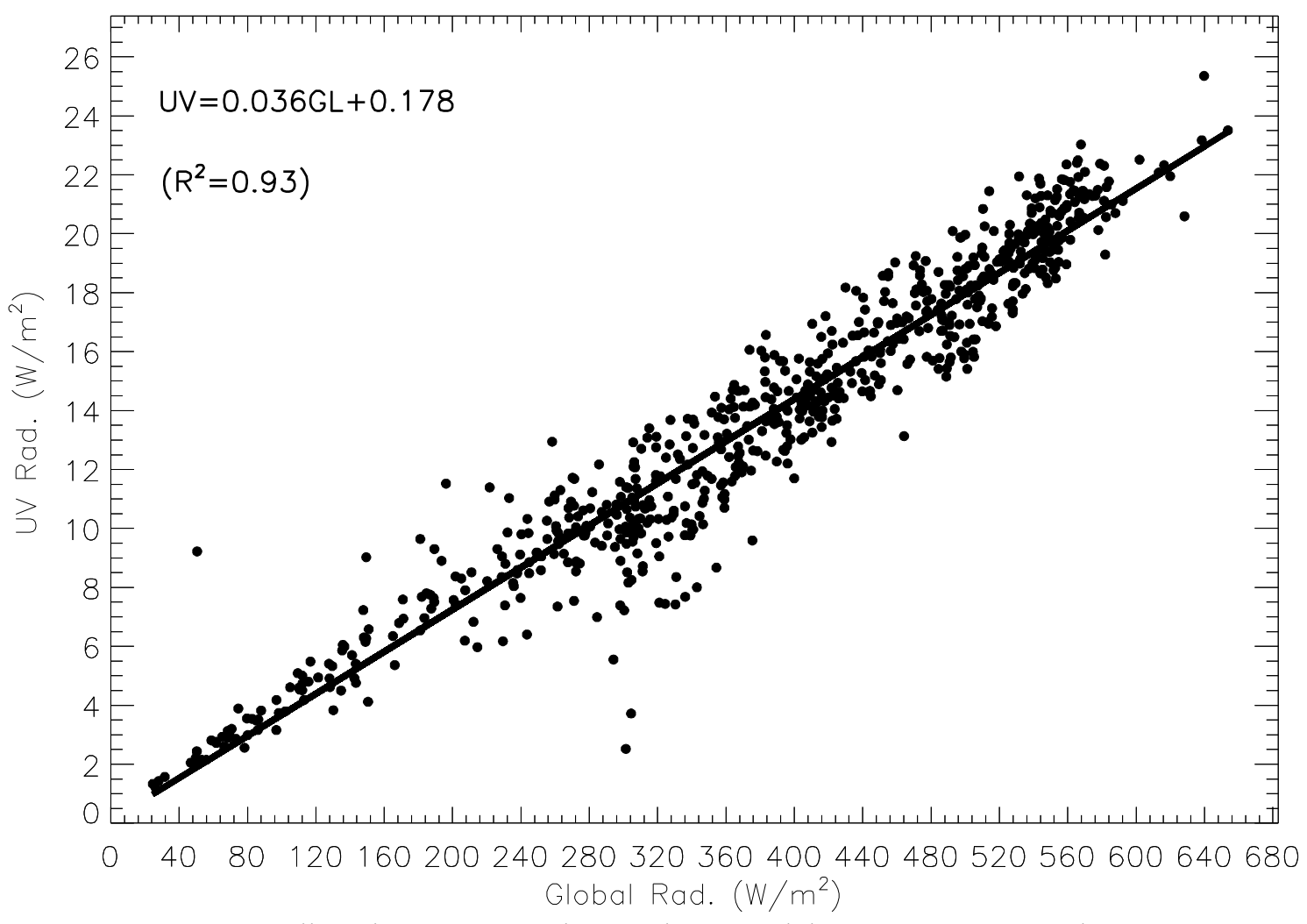

Şekil 5. 2015-2016 yıllarında güneşten gelen ortalama günlük UV 1şınımının toplam 1şınıma göre değişimi.

Günlük ortalama UV 1şınım verileri kullanılarak 2015 ve 2016 yıllarına ait iki yıllık aylık ortalama UV 1şınım değişimi incelenmiş ve elde edilen sonuçlar ve 2015 ve 2016 yıllarının ortalaması Tablo 1'de verilmiştir. Tablo 1 incelendiğinde Ocak 2015'de 7.50 $\mathrm{W} / \mathrm{m}^{2}$ ve Aralık 2016' da $5.50 \mathrm{~W} / \mathrm{m}^{2}$ en düşük UV 1şınım değerleri ölçülürken, Haziran 2015 'de $19.56 \mathrm{~W} / \mathrm{m}^{2}$ ve Temmuz 2016 ' de $19.50 \mathrm{~W} / \mathrm{m}^{2}$ ile en yüksek değer ölçülmüştür. Tablo 1'de verilen iki yıllık aylık ortalamaların sütunlar şeklindeki değişim grafiği ise Şekil 6'da verilmiştir. Şekil 6'da kırmızı, mavi ve yeşil sütunlar sırasıyla 2015, 2016 ve iki yıllık ortalama değerlerini göstermektedir. UV ışınımının değişimi Ocak ayından (ortalama $7.54 \mathrm{~W} / \mathrm{m}^{2}$ ) başlayarak artmaya başlamış ve Temmuz ayında maksimuma (ortalama $19.41 \mathrm{~W} / \mathrm{m}^{2}$ ) ulaşmış ve daha sonra tekrar azalmaya başlayarak Aralık ayında en düşük değerine (ortalama $7.30 \mathrm{~W} / \mathrm{m}^{2}$ ) düşmüştür.

2015-2016 yılları arasında ölçülen UV ışınımın saatlik verileri kullanılarak aylara göre saatlik değişimleri elde edilmiş ve sonuçlar Tablo 2 ve Şekil 7'de verilmiştir. Şekil 7 incelendiğinde tüm aylarda güneş ufuk düzleminden yükselmeye başladığında UV 1şınımı da artmaya başlamakta ve öğlen saatlerinde en yüksek şiddete ulaşmaktadır. Daha sonra akşam saatlerinde tekrar en düşük seviyesine gelmektedir. UV 1şınımının en düşük olduğu Aralık ayında güneş sabah saat 06:40 civarında doğmakta ve 16:20 civarında da batmaktadır. Sabah ve akşam saatlerinde ölçülen UV ışınımın ortalama değerleri sırasıyla $1.83 \mathrm{~W} / \mathrm{m}^{2}$ ve $0.32 \mathrm{~W} / \mathrm{m}^{2}$ ve öğlen saat 11:00-12:00 arasında 12.35 $\mathrm{W} / \mathrm{m}^{2}$ ile maksimum olmuştur. Aralık ayındaki günlük olarak ortalama UV toplamı $70.78 \mathrm{~W} / \mathrm{m}^{2}$ ve günlük ortalaması ise $6.43 \mathrm{~W} / \mathrm{m}^{2}$ olarak ölçülmüştür. 
Tablo 1. 2015 ve 2016 yıllarına ait aylık olarak ortalama UV ışınımı ve bunların ortalama değerleri

\begin{tabular}{|c|c|c|c|}
\hline Aylar & $\begin{array}{c}\mathbf{2 0 1 5} \\
\left.\mathrm{W} / \mathrm{m}^{2}\right)\end{array}$ & $\begin{array}{c}\mathbf{2 0 1 6} \\
\left.\mathrm{W} / \mathrm{m}^{2}\right)\end{array}$ & $\begin{array}{l}\text { Ortalama } \\
\left(\mathrm{W} / \mathrm{m}^{2}\right)\end{array}$ \\
\hline Ocak & 7.50 & 7.82 & 7.66 \\
\hline Subat & 8.86 & 10.04 & 9.45 \\
\hline Mart & 12.71 & 13.84 & 13.28 \\
\hline Nisan & 15.43 & 16.70 & 16.07 \\
\hline Mayıs & 19.54 & 17.77 & 18.66 \\
\hline Haziran & 19.56 & 19.09 & 19.33 \\
\hline Temmuz & 19.31 & 19.50 & 19.41 \\
\hline Ağustos & 17.40 & 16.83 & 17.12 \\
\hline Eylül & 13.60 & 15.65 & 14.63 \\
\hline Ekim & 11.66 & 13.13 & 12.40 \\
\hline Kasım & 11.86 & 10.53 & 11.20 \\
\hline Aralık & 9.10 & 5.50 & 7.30 \\
\hline
\end{tabular}

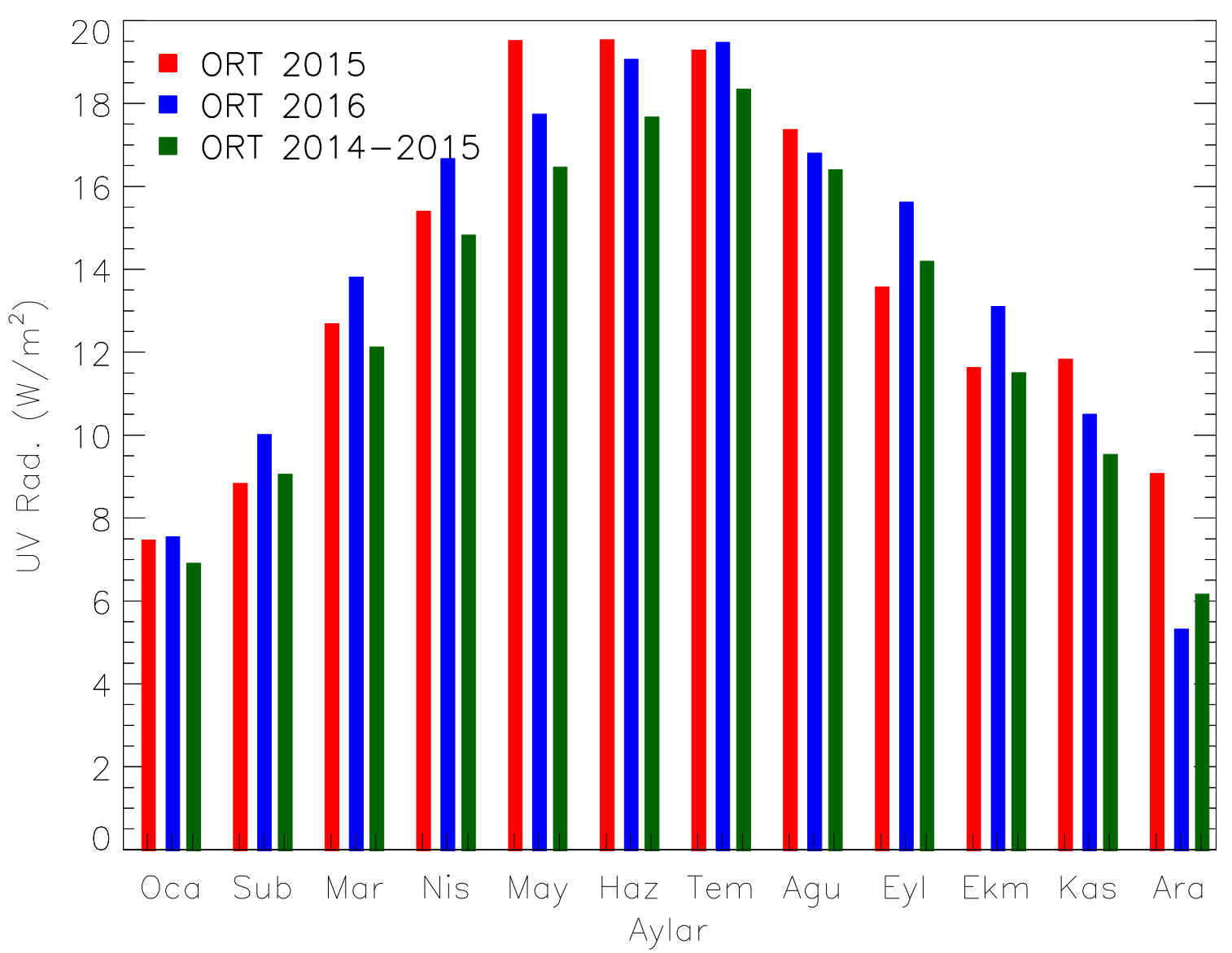

Şekil 6. 2015 ve 2016 yıllarına ait aylık olarak ortalama UV ışınımı değişımi

Benzer şekilde Ocak ayında da güneşlenme süresi en düşük olduğundan sabah 06:47'de güneş doğmakta ve saat 06:00-07:00 aralığında yaklaşık olarak $0.48 \mathrm{~W} / \mathrm{m}^{2}$ iken akşam saat 16:40 civarında da batmakta ve gelen UV 1şınım miktarı ise $0.57 \mathrm{~W} / \mathrm{m}^{2}$ olmaktadır. Ocak ayında güneş 1şınımın 12:00-13:00 saatleri arasındaki en yüksek olduğu değer $11.50 \mathrm{~W} / \mathrm{m}^{2}$ olarak ölçülmüştür. Ocak ayında UV 1şınımların gün boyunca toplamı $69.79 \mathrm{~W} / \mathrm{m}^{2}$ ve günlük ortalaması ise $5.82 \mathrm{~W} / \mathrm{m}^{2}$ olarak belirlenmiştir. Aynı şekilde, Tablo 2'de ve Şekil 7'de görüldüğü gibi Haziran ayında güneş ortalama saat 05:14'te doğmakta ve 19:56'da batmaktadır. Sabah 05:00-06:00 aralığında ölçülen ortalama UV miktarı $0.96 \mathrm{~W} / \mathrm{m}^{2}$ iken güneşin tepede olduğu 12:00-13:00 arasinda $33.00 \mathrm{~W} / \mathrm{m}^{2}$ olmakta ve tekrar azalarak akşam saatlerinde 19:00-20:00 arasında $0.77 \mathrm{~W} / \mathrm{m}^{2}$ düştüğü 
görülmektedir. En uzun güneşlenme süresine eşit olan Haziran ayında gün boyunca toplam $250.93 \mathrm{~W} / \mathrm{m}^{2}$ kadarlık (ortalama $16.73 \mathrm{~W} / \mathrm{m}^{2}$ ) UV 1şınımı ölçülürken Temmuz ayında ise UV 1şınım toplamı 262. $20 \mathrm{~W} / \mathrm{m}^{2}$ iken ortalama $17.48 \mathrm{~W} / \mathrm{m}^{2}$ olarak ölçülmüştür.

Tablo 2. 2015- 2016 yılları arasında ölçülen UV 1şınımının aylık ortalamasının $\left(\mathrm{W} / \mathrm{m}^{2}\right)$ saatlere göre değişimi

\begin{tabular}{ccccccccccccc}
\hline Saat\Ay & Oca & Şub & Mar & Nis & May & Haz & Tem & A ̆gu & Eyl & Eki & Kas & Ara \\
\hline $05-06$ & & & & 0.55 & 0.76 & 0.96 & 0.60 & 0.39 & & & & \\
$06-07$ & & & 1.38 & 1.59 & 3.56 & 4.07 & 3.15 & 2.09 & 1.05 & 0.57 & & \\
$07-08$ & 1.37 & 1.98 & 4.31 & 5.53 & 8.88 & 9.00 & 8.47 & 6.62 & 4.54 & 2.57 & 2.66 & 1.83 \\
$08-09$ & 3.95 & 5.11 & 8.80 & 10.98 & 15.44 & 15.26 & 15.20 & 13.00 & 9.87 & 7.08 & 6.73 & 4.99 \\
$09-10$ & 7.26 & 8.88 & 13.62 & 17.06 & 21.33 & 21.70 & 21.78 & 19.91 & 15.98 & 12.27 & 11.41 & 8.63 \\
$10-11$ & 9.84 & 12.4 & 17.51 & 21.83 & 25.90 & 26.32 & 27.93 & 26.10 & 20.57 & 16.61 & 15.13 & 11.3 \\
$11-12$ & 11.0 & 14.0 & 20.60 & 24.69 & 29.07 & 30.13 & 32.92 & 29.54 & 24.01 & 18.67 & 16.93 & 12.3 \\
$12-13$ & 11.5 & 14.3 & 20.34 & 25.21 & 31.00 & 33.00 & 34.51 & 31.30 & 25.33 & 18.59 & 16.17 & 11.5 \\
$13-14$ & 10.0 & 12.3 & 18.34 & 23.45 & 29.98 & 31.92 & 33.56 & 30.28 & 24.17 & 17.44 & 13.92 & 9.65 \\
$14-15$ & 7.34 & 9.95 & 15.05 & 21.44 & 28.09 & 27.70 & 30.08 & 26.74 & 20.49 & 14.49 & 9.85 & 6.38 \\
$15-16$ & 4.51 & 6.51 & 10.98 & 16.84 & 22.19 & 22.05 & 23.94 & 20.66 & 14.74 & 9.86 & 5.03 & 3.00 \\
$16-17$ & 1.76 & 3.12 & 5.66 & 10.73 & 14.30 & 15.56 & 16.36 & 13.47 & 8.35 & 4.45 & 1.64 & 0.75 \\
$17-18$ & 0.72 & 0.81 & 1.88 & 5.26 & 7.85 & 8.98 & 9.21 & 6.93 & 3.08 & 0.95 & 0.95 & 0.32 \\
$18-19$ & & 0.26 & 0.76 & 1.30 & 2.92 & 3.53 & 3.67 & 2.00 & 0.55 & 0.71 & & \\
$19-20$ & & & & 0.47 & 0.52 & 0.77 & 0.80 & 0.58 & & & & \\
Toplam & 69.3 & 89.8 & 139.2 & 186.9 & 241.8 & 250.9 & 262.2 & 229.6 & 172.7 & 124.2 & 100.4 & 70.7 \\
\hline
\end{tabular}

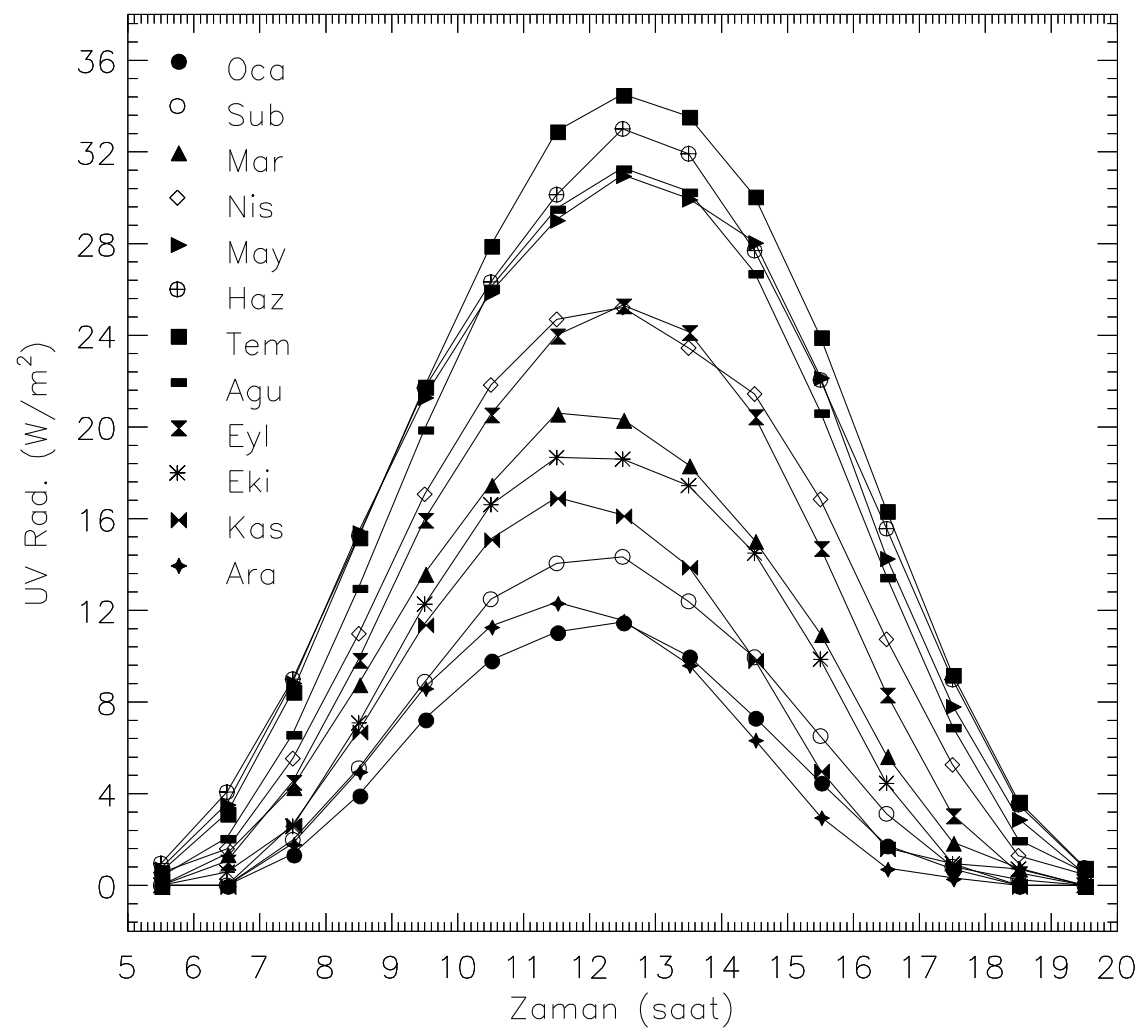

Şekil 7. 2015-2016 yılları arasında ölçülen aylık olarak ortalama saatlik UV ışınım değişimi. 


\section{Sonuç ve Yorum}

Güneşten gelen UV enerjisi verilerinin insan sağlığına olan etkilerinden dolayı bölgesel olarak sürekli takip edilmesi gerekmektedir. Bu nedenle, güneşten gelen UV 1şınımı dünyanın pek çok bölgesinde bölgesel olarak çalışılmaktadır. Bu amaç doğrultusunda Osmaniye Korkut Ata Üniversitesi Karacaoğlan yerleşkesinde $\left(37^{\circ} .042 \mathrm{~K}\right.$, Boylam: 36 .22D) bulunan UV Radyometre ile Mayıs 2013 tarihinden itibaren UV 1şınımını dakikalık olarak $\mathrm{mV}$ cinsinden günlük ölçülmekte ve veri arşivi oluşturulmaktadır. $\mathrm{Bu}$ çalışmada, Ocak 2015- Aralık 2016 tarihleri arasındaki alınan 717 günlük veri analiz edilmiştir. Dakikalık olarak $\mathrm{mV}$ cinsinden alınan verilerin kalibrasyonları yapılarak günlük ve aylık olarak enerji birimine $\left(\mathrm{W} / \mathrm{m}^{2}\right)$ dönüştürülmüştür.

2015 yılında günlük UV 1şınım enerji toplam $5051.31 \mathrm{~W} / \mathrm{m}^{2}$ ve günlük ortalama $13.83 \mathrm{~W} / \mathrm{m}^{2}$ olarak ölçülürken, 2016 y1lında toplam $4890.35 \mathrm{~W} / \mathrm{m}^{2}$ ve günlük ortalama $13.89 \mathrm{~W} / \mathrm{m}^{2}$ olarak ölçülmüştür. İki yıllık verilerin günlük olarak ortalaması alındığında yıllık olarak toplam UV miktarı $5027.49 \mathrm{~W} / \mathrm{m}^{2}$ ve ortalaması da ise $13.77 \mathrm{~W} / \mathrm{m}^{2}$ olarak belirlenmiştir. UV ışınımın 2015 yılında en yüksek 25 Haziran'da $25.28 \mathrm{~W} / \mathrm{m}^{2}$ olarak ölçülürken, 2016 yılında 21 Temmuz' da $22.55 \mathrm{~W} / \mathrm{m}^{2}$ olarak yaz aylarında ölçülmüştür.

Yapılan çalışma sonucuna göre, ölçüm süresince güneşten gelen günlük UV 1şınım ile toplam 1şınım arasında " $U V=0.0336 G L+0.178$ " gibi bir ilişkinin olduğu görülmüştür.

Yukarıda belirtildiği gibi yeryüzüne gelen UV 1şınım miktarı toplam ışınımın yaklaşık \% 5'lik çok küçük bir kesrini oluşturmaktadır [4,5]. Ölçüm süresince UV 1şınımın saatlik verileri kullanılarak aylara göre saatlik değişimleri incelenmiş ve güneşlenme süresinin en uzun olduğu Haziran ayında günlük toplam UV 1şınım miktarı $250.93 \mathrm{~W} / \mathrm{m}^{2}$ kadarlık UV 1şınımı ölçülmüştür. Haziran ve Temmuz aylarında saat 12-13 arası ortalama $33.76 \mathrm{~W} / \mathrm{m}^{2}$ ile en yüksek UV ışınımı ölçülmüştür.

Elde edilen sonuçlara göre, Ocak, Şubat, Mart, Ekim, Kasım ve Aralık aylarında günlük ortalama UV ışınım miktarı $20 \mathrm{~W} / \mathrm{m}^{2}$ 'nin altında iken diğer Nisan, Mayıs, Haziran, Temmuz ve Ağustos aylarında saat 08:00 ile 16:00 saatleri arasında $10 \mathrm{~W} / \mathrm{m}^{2}$ ile yaklaşık $30 \mathrm{~W} / \mathrm{m}^{2}$ arasında değiştiği görülmüştür.

Sonuç olarak, yaz aylarında yüzeye gelen güneşin UV ışınımın şiddeti özellikle sabah saat 10:00 ile akşam saat 14:00 arasına en yüksek düzeye ulaştı̆̆ gözlenmiştir. Bu saatler arasında güneş ışınlarına fazla maruz kalmamak gerekmektedir. Gelecekte bölgesel olarak günlük, aylık ve yıllık değişimlerinin uzun süreli takip edilmesine devam edilecektir.

\section{Kaynakça}

[1] B. L. Diffey, "Solar ultraviolet radiation effects on biological systems," Review in Physics in Medicine and Biology, 36(3), 299-328 1991.

[2] A. Serrano, M. Anton, M. L. Cancillo, and V. L. Mateos, "Daily and annual variations of erythemal ultraviolet radiation in Southwestern Spain," Annales Geophysicae, 24, 427-441, 2006.

[3] J. B. Kerr, "Understanding the factors that affect surface ultraviolet radiation," Optical Engineering, 44 (4), 041002-1-8, 2005.

[4] M. Iqbal, An Introduction to Solar Radiation, Academic Press, Toronto, Canada, 1983.

[5] M. Nunez, B. Forgan, and C. Roy, "Estimating ultraviolet radiation at the earth's surface", International Journal of Biometeorology, 38(1), 5-17, 1994.

[6] A. M. El Nouby, "Effect of Stratospheric Ozone in UVB Solar Radiation Reaching the Earth's Surface at Qena, Egypt," Atmospheric Pollution Research, 1(3):155-160, 2010.

[7] B. L. Diffey, "Sources and measurement of ultraviolet radiation," Methods, 28 (1) 4-13, 2002. 
[8] C. R. Roy, H. P. Gies, and S. Toomey, “The Measurement of Solar Ultraviolet radiation,", Mutation Research/Fundamental and Molecular Mechanisms of Mutagenesis, 422 (1): 7-14, 1998.

[9] M. Şahan, H. Şahan ve İ. Yegingil, "Yıllık toplam ve Ultraviole (UV) Güneş Enerjisi Verilerinin Ölçülmesi”, Süleyman Demirel Üniversitesi, Fen Bilimleri Enstitüsü Dergisi, 14 (1), 10-16, 2010.

[10] M. Şahan, "Measurement of Daily Solar Radiation with Eppley Black and White Pyranometer in Osmaniye Region, Turkey", AIP Conference Proceedings 2018, 2042, pp. 020005-1-0200054. 